\title{
KNOWLEDGE MANAGEMENT OF THE ESP CLASS USING TECHNOLOGY
}

\author{
Irina Ioana BOCIANU \\ University of Bucharest, Bucharest, Romania \\ irina.bocianu@lls.unibuc.ro
}

\begin{abstract}
The present study aims at analyzing the benefits and drawbacks of knowledge management of the ESP class through the use of technology. Being in constant contact with technology, it is unavoidable to use it for teaching foreign languages. For this reason, both CALL (Computer Assisted Language Learning) and mobile apps prove useful in the demarche for better teaching and learning process. Nevertheless, managing blended learning ESP class implies a different approach to technology that goes beyond the classic use of Web 2.0 tools and proposes a new generation of mobile technology that facilitates and even simplifies the acquisition of all the four competencies (for ESP): reading, writing, listening and speaking for students ranging $A 2$ to $C 1$ (usually few students are absolute beginners and other few have native-like English level) in compliance with the Common European Framework of Reference for Languages whose guidance aids instructors prepare students for the competitive labor market.
\end{abstract}

\section{Keywords: knowledge management, ESP, technology, teaching/learning process}

\section{Introduction}

In higher education, to manage the knowledge input is a challenge which affects all subjects of study, and ESP alike. ESP (English for Specific Purposes) goes beyond EGP (English for General Purposes) as it implies the appropriation of specific vocabulary of each specialization. In the present case, the study focuses on the students from the University of Bucharest European Studies, Law and Chemistry specializations addressing the issue of teaching specific terminology enhanced by technology. Thus, knowledge appropriation is the ESP class has to take advantage of any available tools that facilitate content delivery within the teaching/learning process. For this reason, technology is much appreciated in the teaching of foreign languages. Nevertheless, it comes with a series of drawback that can impair the educational process. The present study further analyses how the use of these technological developments aid both the instructor and the student apprehend ESP and how knowledge is managed when technology is employed.

\subsection{EPS and Technology}

ESP has a long history with the use of technology starting from the old-time use of video cassettes and audio materials to the use of the latest mobile technology. As of 2018, one can notice the rapid transition from the Web 2.0 tools towards more mobile applications which are highly used as a teaching/learning tool. Before going into a more detailed analysis of how technology is used for the teaching/learning process, it is worth detailing what ESP and technology are and how knowledge management can be related to them.

Tom Hutchinson and Alan Waters have defined ESP as the object of learning and that language has come to be the focus rather than the means to convey the 
message: "EPS, like any form of language teaching, is primarily concerned with learning. But it is our view that in its development up to now, ESP has paid scant attention to the question of how people learn, focusing instead on the question of what people learn. It has, in other words, been language-centred in its approach" [1]. Nevertheless, this has to be complemented with the necessary tools in order to reach its goals. Another important issue regarding ESP further developed by Hutchinson and Waters is the students' needs and needs acknowledgement as these ESP classes usually address adults who were in the situation to know precisely what they are learning and why - that is, what motivates them to study specialised terminology. Hutchinson and Waters state: "Learners were seen to have different needs and interests, which would have an important influence on their motivation to learn and therefore on the effectiveness of their learning. This lent support to the development of courses in which "relevance" to the learners' needs and interests was paramount" [1].

Later on, in 2006 Elisabet Arno Marcia, Antonia Soler Cervera and Carmen Rueda Ramos have become concerned how technology-integrated ESP classes are more effective for the appropriation of specific content. They make a very useful distinction between CALL (ComputerMediated Language Learning and NBLT (Network-based language learning): "Although NBLT is part of CALL, the latter is usually associated with the use of computers with self-contained material, whereas NBLT focuses on human-tohuman communication in which the computer is a tool" [2]. They also approach the importance of ESP and how the development of technological skills associated with the learning process contribute to the development of communication in the professional contexts: "From the perspective of LSP (Language for Specific Purposes) teachers and learners, information technology plays a key role in developing strategies for effective communication, both in academic and professional settings. In this everchanging and fast-paced world, the demands and skills associated with professional practices need to be integrated into the teaching of academic and professional communication. As a result, we consider the professional communicator as an information manager, who needs technology as a tool for communication as much as for his or her own professional practice" [2].

Thus, the above -mentioned authors make a major point as the integration of technology within the teaching/learning process is of utmost importance for the management of information and content delivery for knowledge management.

\subsection{Knowledge management}

In order to achieve the desired results, knowledge management plays a significant role. If knowledge is properly managed, then information is transmitted and appropriated so that it fulfils its role - in this case well prepared students for the European labour market [3]. This is relevant in a sense that it guides the instructor into the students' language levels. Nevertheless, as students have an average level of English - B1 or B2 - with few exceptions of the students who are A2 or $\mathrm{C} 1$ or $\mathrm{C} 2$, it is quite important to deliver the specific content accordingly.

In 1998 O'Dell and Greyson defined knowledge management as "conscious strategy of getting the right knowledge to the right people in the right time and helping people share and put information into action" [4]. At the same time, Devenport and Prusak state that knowledge management derives from the already existing resources within the organisation [5]. In the case of education, the students' level of English is the existing resource while the utilization of technology is the facilitator for the information transmission 
for its appropriation. In 2003 Petrides and Nodine define knowledge management in education as "a set of practices that helps to improve the use of and sharing of data and information in decision-making" [6]. Nevertheless, W.R. King's definition is even more comprehensive as it summarises the core meaning of knowledge management: "Knowledge management is the planning, organizing, motivating, and controlling of people, processes and systems in the organization to ensure that its knowledge-related assets are improved and effectively employed" [7].

In the higher education environment, to manage knowledge is very important. Firstly, it is highly recommended to be done in accordance with the European Framework of Languages. Secondly, how it is done is also relevant for the recipients. Under these circumstances, the means for content delivery is as important as the content itself. That is, the facilitation offered by technology for specialised vocabulary development is undeniable. One example would be that content can be delivered within a dull text, which would make students quite inattentive, bored and lost in specialised terminology or it could be delivered as a YouTube video which approaches the same topic in a more dynamic, appealing and pleasant way. In both cases, how content is delivered is more important than the content itself as this makes the difference of metacognition strategies - inducing the students into motivating themselves to learn as they enjoy the means information is transmitted.

\section{Video content and listening in the ESP class}

The use of technology in the ESP class has evolved from VHS recordings to the YouTube and other video content dedicated to various subjects and delivered by experts in certain fields - Ted Talks. The advantage of using these videos is represented by the fact that up-to-date and state-of-the art content is delivered. Thus, students are exposed to information of their interest of study, become more interested in the subject and even develop more in their future endeavours. One good example would be the fact that the chemistry students, after watching Ted Talks on corals chemistry, have decided to develop the subject - and delivered a talk on the subject for the Students' Conference.

Besides being a source of up-to-date information in the field, delivered in a wellstructured, dynamic manner, students are exposed to the speakers' different accents which is quite a challenge during the languages class. Using technology during the ESP classes has lots of benefits for language appropriation. Not only listening skills are challenged and developed, but also vocabulary building is quite an important part of the activity. After watching the video, the students are asked to answer few general comprehension questions. After the completion of this activity, more complex and detailed questions are asked. During this activity, students have to identify specific information and answer detailed questions. This activity also determines students to understand new terminology and unknown words. This activity is done in small bits after the first vision of the bulk clip. These activities challenge the students' attention for details. Here, besides new terminology, synonyms, antonyms are checked. Also, the task allows the instructor to check numbers, percent, graphs and any other exercises that can be applied according to the specifics of the video. At the end of the activity, as a round off, students have to provide their own opinions on the subject. Sometimes, this is done either by asking students to provide a 5-line precis, or to deliver a 2minute presentation on a specific question addressing the subject of the clip. At times, students are asked to develop parts of the subject as homework if the subject is interesting for them. Another activity which as an instructor I found quite useful is to generate debate on the subject discussed. 
As the students have already been exposed to the information delivered in the video, they are divided into two groups. One group is asked to bring up arguments "for" and the other groups is asked to bring arguments "against". Students are divided in groups of 3 or 4 and. This activity is quite challenging, as students have to provide supporting ideas on subjects that they actually think the opposite of. After the groups present their "for" and "against" arguments, there is a general discussion and debate takes place. This is quite an interesting activity to work on with the students and their debating skills are tested. As a round off activity, the students are communicated their good and to-beimproved approaches to the topic and debating abilities. All in all, the video content provided in the ESP class is beneficial and a great array of activities can be carried out deriving from watching a clip.

Nevertheless, one drawback exists: the lack of technology in the room is quite a challenge. But, as we are living in a highly technologized society, the possibility to access the video content via the students' smart phones makes the drawback of lacking an overhead video projector as less of a disadvantage but rather a small impediment. In situations like this, students are asked to stay together in groups of 3 or 4 and watch the clip. This activity is performed either in all class activity when I usually bring a portable speaker which I connect to my mobile phone and everybody starts watching at a certain signal, or students watch together at their own pace. Usually, in these situations students are asked to use the English subtitles in order to better understand the speakers. Thus, solutions are provided by the mobile technology which can be very useful in the class. Other disadvantages might be represented by the short lived batteries that smart phones are provided with, and which discharge quite fast when video clips are played. Some students bring external batteries especially for these situations. All in all, watching video clips for teaching purposes during the ESP class is an activity which remains specific for language teaching and, the more advanced the technology, the more one should take advantage of it in the class.

Regarding the listening activities, these are done also with the aid of technology. After transferring the materials from the $\mathrm{CD}$ to the computer, the content is generally uploaded to drive offered by Google or to the memory card in my smart phone. Thus, whenever listening activities occur in the manual, the portable speaker is connected to my smartphone and listening is done during the class. This new approach to listening has occurred out of the need to practice listening skills with the students in rooms where no technical equipment is available. Also, the fact that I teach ESP means that I have to migrate to each faculty I have to deliver classes to. Not all rooms are provided with the necessary technology and carrying a CD player all over the campus would be quite an exhausting activity. So, taking advantage of the available resources is the best way in order to practice all skills necessary for the foreign languages acquisition. Thus, adaptation to the latest technology by using the handiest tools available is key to successful language classes when technology is missing. Students are also happy to use mobile technology in the class as it is part of their everyday lives and defines them a new generation of "digital natives" [8]. Not only does this keep students' attention in focus for the class, but they become more active - it is much entertaining to watch a video on a certain subject than read a boring text.

\section{Conclusions}

The use of technology in the ESP class has a long tradition. At the same time, it has to be updated to the nowadays technological developments and used as a teaching tool even when impaired by objective factors 
and logistics. For this reason, it is highly recommended to transfer to mobile as it is handy and facilitates the development of activities which otherwise would be impossible to approach. The use of mobile technology not only facilitates the teaching/learning process, but it also makes it more appealing for the students and thus apprehension is done much easier and more interactive. At the same time, using mobile technology more than CALL in the class makes students use technology for other purposes than surfing the internet for Facebook or WhatsApp. It helps students develop skills of using technology for learning and for searching of information that is part of their field of study. It also prepares students for the labour market because the lack of something - in this case technology - obliges instructors/students to find solutions, which makes them even more self-confident as all barriers can be crossed. This way, the instructor manages knowledge regardless of the environment and tools available and students apprehend skills outside the curricula, knowledge is properly delivered and effective use is made out of it.

\section{References}

[1] Hutchinson, T. and Waters A., English for Specific Purposes - A learning-centred approach, online, Cambridge, Cambridge University Press, 1991, pp. 7-8.

[2] Marcia, E.A., Cervera, A.S. and Ramos, R.C., Information Technology in Languages for Specific Purposes, Issues and Prospects, online, New York, Springer Science + Business Media Inc., 2006, pp. 10-11.

[3] http://eeas.europa.eu

[4] O'Dell, C. and Greyson C.J. If only we knew what we know: the transfer of internal knowledge and best practice, California Management Review, Vol. 40, No. 3, pp 154$174,1998$.

[5] Devenport T.H. and Prusak L., Working knowledge: how organizations manage what they know, online, Massachusetts, Boston, Mass: Harvard Business School Press, pp.163.

[6] Petrides L.A. and Nodine T.R., Knowledge Management in Education: Defining the Landscape, online, No. 477 349, ERIC Publishing, pp. 1-34.

[7] King, W.R., Knowledge Management and Organizational Learning, Annals of Information Systems 4, Springer Science and Business, 2009, 3-13.

[8] Prensky, M., Vol. 9, No.5, pp. 1-6, 2001. 